\title{
Effect of Post-Exercise Sauna Bathing on Targeted Gut Microbiota and Intestinal Barrier Function in Healthy Men: A Randomized Controlled Trial
}

Joanna Karolkiewicz ( $\nabla$ karolkiewicz@awf.poznan.pl)

Poznan University of Physical Education

David C. Nieman

Appalachian State University

Tomasz Cisoń

State University of Applied Sciences in Nowy Sącz

Joanna Szurkowska

Poznan University of Physical Education

Mirosława Gałęcka

Institute of Microecology, Poznan

Dariusz Sitkowski

Institute of Sport - National Research Institute

Zbigniew Szygula

University School of Physical Education in Kraków

\section{Research Article}

Keywords: gut microbiota, exercise, sauna bathing, intestinal barrier function

Posted Date: July 7th, 2021

DOl: https://doi.org/10.21203/rs.3.rs-671562/v1

License: (c) (i) This work is licensed under a Creative Commons Attribution 4.0 International License.

Read Full License 


\section{Abstract}

Background: Body temperature fluctuations induced by acute exercise bouts may also influence the intestinal barrier with related effects on epithelial permeability, immune responses, and release of metabolites produced by the gut microbiota.To evaluate the combined influence of 4-weeks exercise training and post-exercise sauna treatments on gut bacteria and fungi, inflammation, and intestinal barrier function.

Methods: Randomized, parallel group design with pre- and post-study measurements.

Fifteen (15) untrained males aged $22 \pm 1.5$ years were randomly assigned to exercise training (ET) with or without post-exercise sauna treatments (S). Participants in the group ET+S $(n=8)$ exercised 60 minutes, 3 times per week, on a bicycle ergometer followed by a 30-minute dry Finish sauna treatment. The control group ( $E T, n=7)$ engaged in the same exercise training program without the sauna treatments. Blood and stool samples were collected before and after the 4-week training program. Blood samples were analysed for the concentration of high-sensitivity C-reactive protein (hsCRP) and complete blood counts. Stool samples were analysed for $\mathrm{pH}$, quantitative and qualitative measures of targeted bacteria and fungi, zonulin, and secretory immunoglobulin A. Group comparisons showed no significant differences for blood and stool sample measurements during the 4-week study.

Results: Group comparisons showed no significant differences for blood and stool sample measurements during the 4-week study.

Conclusions: The combination of 4-weeks exercise training and post-exercise sauna treatments did not have a measurable influence on targeted gut microbiota, intestinal barrier function, and inflammation biomarkers in young males compared to exercise training alone.

\section{Background}

Strategies for exercise recovery are numerous, and include stretching, mild exercise, massage, nutrition and hydration, sleep, water therapy, and hot or cold treatments (1). Sauna bathing has been linked to multiple health benefits (2)(3) and is widely used by athletes (4),(5).

The relationship between exercise training and the gut microbiota is complex and perhaps bidirectional. Although human data are still emerging, the gut microbiome may be influenced by exercise training, but at the same time the gut microbiome may modify training-induced physiological adaptations (6),(7),(8). Body temperature fluctuations induced by acute exercise bouts may also influence the intestinal barrier with related effects on epithelial permeability, immune responses, and release of metabolites produced by the gut microbiota (9).

Scant evidence suggest that thermal therapy may also have an influence on the gut microbiome. Environmental temperature and heat stress can modify the gut microbiome composition and function 
(10). These data imply that thermal therapies such as sauna bathing may influence the gut microbiome. To date, there is little information on whether thermal therapy exerts positive or negative effects on the microbiome. This is an interesting question because of the immunological effects of thermal therapies, and the potential interactive effects with exercise training.

Taken together, both exercise training and sauna bathing have the potential to influence gut permeability, inflammation, and the gut microbiota. The aim of this study was to evaluate the effects of post-exercise sauna bathing in young men undergoing endurance training on the targeted gut microbiota and intestinal barrier function.

\section{Methods}

\section{Participants}

Study participants included 15 young healthy men aged $22 \pm 1.5$ years. The study inclusion criteria included voluntary written consent, absence of medical contraindications, no history of infections, and no injuries in the last 4 weeks prior to the study. Exclusion criteria including the intake of antibiotics, steroids, oral antifungal agents (except for topical antifungals), antiparasitic agents, pre- and/or probiotics, history of travel to tropical countries during the last 4 weeks before the study, and history of adverse responses to sauna bathing.

\section{Procedure}

This study utilized a randomized, parallel group design. The participants were randomly assigned to exercise training (ET) with or without post-exercise sauna treatments (S). Participants in the group ET $+S$ $(n=8)$ exercised 60 minutes, 3 times per week, on a bicycle ergometer followed by a 30-minute dry sauna treatment. The control group $(E T, n=7)$ engaged in the same exercise training program without the sauna treatments. The 60-minute exercise bouts were performed on calibrated Keiser M3 ergometers (Germany). The initial exercise intensity was set at $50 \% \mathrm{VO}_{2}$ peak for 2 weeks, and then increased to $60 \%$ for the final two weeks of training. The physical exercise was performed in controlled environmental conditions (temperature of $22-23^{\circ} \mathrm{C}$, and relative humidity of $30-33 \%$ ) with no use of fans or cold drinks. Immediately after finishing the 60-minute exercise bout, subjects from group ET + S spent 30 minutes in a dry sauna (in the sitting position), at a temperature of approximately $90^{\circ} \mathrm{C}$ at the chest level and relative humidity of air $10 \pm 2 \%$. The sauna treatment was divided into two or three parts (e.g. $3 \times 10$ minutes, $2 \times$ 15 minutes), and subjects were allowed to cool the body for a maximum of 3-min (e.g. by taking a cold shower, immersing the body in cool water up to the armpits).

Participants agreed to maintain normal dietary intake patterns, and this was verified with 3-day food records at the beginning and end of the 4-week study. Energy and nutrient intake was calculated using the NUVERO application.

\section{Peak oxygen uptake}


Peak oxygen uptake (VO2peak) was assessed with MetaMax 3B analyzer (Cortex, Germany) before and after the 4-week study using a graded exercise test with a cycloergometer Cyclus2 (Avantronic, Germany). Metabolic measurements included ventilation (VE), oxygen consumption (VO2), carbon dioxide production (VCO2), and heart rate (HR).

\section{Body composition assessment}

Body mass, height, and body composition were measured before and after the 4-week study. Body mass was measured using a certified medical digital beam scale WB-3000 (TANITA Corporation, Tokyo, Japan). Height was measured with a mechanical measuring rod HR-001 (TANITA Corporation, Tokyo, Japan). Body composition was measured in the fasting state using a GE Lunar Prodigy Primo Full Densitometer with enCore Body Composition option (GE Healthcare Technologies, USA).

\section{Blood and stool sample collection}

Blood and stool samples were collected before and after the 4-week study. Blood samples (approx. $2 \mathrm{ml}$ ) were taken from the antecubital vein and centrifuged at $4000 \mathrm{rpm}$ and $4^{\circ} \mathrm{C}$. The serum was separated from the sample and stored at $-70^{\circ} \mathrm{C}$. The concentration of high-sensitivity C-reactive protein (hsCRP) was measured by immunoenzymatic assay using a commercially available kit (DRG International Inc., Springfield Township, NJ, USA; test sensitivity: $0.1 \mathrm{mg} / \mathrm{L}$ and $5 \mathrm{ng} / \mathrm{mL}$ ). Complete blood count indices were determined by flow cytometry with a Synergy 2 SIAFRT analyser (Bio Tek, Winooski, VT, USA).

In order to perform qualitative analyses of selected indicator bacteria in the gastrointestinal tract, and to determine the stool $\mathrm{pH}$, the studied men were requested to provide a stool sample within 24 hours of collection. Stool sample collection was performed according to the established protocol developed by KyberKompaktPRO (Institute of Microecology). To this end, a 150-ml sterile container was to be filled to three quarters of its volume with material preferably taken from eight different locations, and closed tightly with a lid. The indicator bacteria, slgA (marker of mucosal immunity), and the concentrations of zonulin (marker of intestinal permeability) in stool were evaluated before and after completing the training programme in both studied groups of men.

Bacterial DNA was isolated from stool samples using the QIAamp Fast DNA Stool Mini Kit (QIAGEN, Danish). An appropriate quantity of stool was weighed into a sterile tube. The isolation of bacterial DNA from the stool sample was performed according to the manufacturer's protocol. The DNA eluates were stored frozen until subsequent analyses.

The anaerobic bacteria including Faecalibacterium prausnitzi of the genus Faecalibacterium, Akkermansia muciniphila of the genus Akkermansia, Bifidobacterium spp. of the genus Actinobacteria, and Bacteroides spp. of the genus Bacteroidetes were determined by Real-Time PCR with appropriate primers (ThermoFisher Scientific, USA) (Table 2). The reaction mixture contained QuantiFast SYBR Green PCR Kit (Qiagen), RNase-free water (Qiagen), and a mixture of forward and reverse primers selected for the bacteria tested. The analyses were conducted in an ABI 7300 analyser (ThermoFisher Scientific, USA). 
Bacterial DNA was isolated from a stool sample using the QIAamp Fast DNA Stool Mini Kit (QIAGEN). To this end, an appropriate quantity of stool was weighed into a sterile tube. The isolation of bacterial DNA from a stool sample was performed according to the manufacturer's protocol. The DNA eluates were stored frozen until subsequent analyses. The counts of anaerobic bacteria including Faecalibacterium prausnitzi of the genus Faecalibacterium, Akkermansia muciniphila of the genus Akkermansia, Bifidobacterium spp. of the genus Actinobacteria, and Bacteroides spp. of the genus Bacteroidetes were determined by Real-Time PCR with appropriate primers (ThermoFisher Scientific) listed in Table 1. The analyses were conducted in an ABI 7300 analyser (ThermoFisher Scientific).

Table 1

Standards applied for the determination of different microorganisms NS: non-significant difference

\begin{tabular}{|lll|}
\hline Name & $\begin{array}{l}\text { Among } \\
\text { of DNA } \\
\text { (copies/ml) }\end{array}$ & Product description \\
\hline $\begin{array}{l}\text { Bifidobacterium } \\
\text { infantis DNA }\end{array}$ & $5 \mathrm{e} 8$ & $\begin{array}{l}\text { Standard in identification of Bifidobacterium spp., isolated } \\
\text { from Bifidobacterium infantis }\end{array}$ \\
\hline $\begin{array}{l}\text { Bacteroides fragilis } \\
\text { DNA }\end{array}$ & $2 \mathrm{e} 9$ & $\begin{array}{l}\text { Standard in identification of Bacteroides spp., isolated from } \\
\text { Bacteroides fragilis }\end{array}$ \\
\hline $\begin{array}{l}\text { Faecalibacterium } \\
\text { prausnitzii DNA }\end{array}$ & $7,8 \mathrm{e} 8$ & Standard in identification of Faecalibacterium prausnitzii \\
\hline $\begin{array}{l}\text { Akkermansia } \\
\text { muciniphila DNA }\end{array}$ & $3,9 \mathrm{e} 8$ & Standard in identification of Akkermansia muciniphila \\
\hline
\end{tabular}

The final bacterial count/g of stool was obtained by converting the number of copies of the sequence amplified by PCR in the bacterial genome (for Faecalibacterium, Akkermansia muciniphila,

Bifidobacterium spp., and Bacteroides spp., respectively) and the dilution factor applicable to the kit used for DNA isolation from stool samples. The conversion factor employed in the study was checked and validated at the Institute of Microecology in Herborn, Germany. Table 1 presents the standards used in the studies.

The limit of detection for the evaluated parameters was $10^{2}$ [CFU/g of feces]. For values below $10^{2}$ [CFU/g of feces] [cut-off point], the value of 0 was adopted for statistical analysis, which, however, does not mean that the test sample was bacteria-free. The results of quantitative bacterial analysis were converted to the decimal logarithm (Log10). The entire Real-Time PCR methodology was developed and validated by the Institute of Microecology in Herborn, Germany. Reference values for selected indicator bacteria and stool $\mathrm{pH}$ are presented in Table 2. 
Table 2

Specific primers used for the determination of different microorganisms

\begin{tabular}{|lll|}
\hline Name & Product description & Sequence \\
\hline Praus-F480 & Faecalibacterium prausnitzii forward starter & CAGCAGCCGCGGTAAA \\
\hline Praus-R631 & Faecalibacterium prausnitzii reverse starter & CTACCTCTGCACTACTCAAGAAA \\
\hline Akk.muc-F & Akkermansia muciniphila starter forward & CAGCACGTGAAGGTGGGGAC \\
\hline Akk.muc-R & Akkermansia muciniphila starter reverse & CCTTGCGGTTGGCTTCAGAT \\
\hline F-Bifid09c & Bifidobacterium spp. forward starter & CGGGTGAGTAATGCGTGACC \\
\hline R-Bifid06 & Bifidobacterium spp. reverse starter & TGATAGGACGCGACCCCA \\
\hline Bacter11 & Bacteroides spp. forward starter & CCTWCGATGGATAGGGGTT \\
\hline Bacter08 & Bacteroides spp. starter reverse & CACGCTACTTGGCTGGTTCAG \\
\hline Uni-F340 & Starter universal forward & ACTCCTACGGGAGGCAGCAGT \\
\hline Uni-R514 & Starter universal revers & ATTACCGCGGCTGCTGGC \\
\hline
\end{tabular}

The evaluation of stool zonulin and secretory immunoglobulin A (slgA) concentrations required sample extraction. A stool extract was prepared using stool collection devices (Stool Sample Application System - SAS, K6998SAS) filled with $0.75 \mathrm{ml}$ of washing buffer warmed to room temperature. Each stool sample was vortexed for homogeneity. In the next step, a stool collection device was inserted into the sample, so that all grooves in the device were filled with stool $(15 \mathrm{mg})$, vortexed and analysed. Zonulin concentrations were assessed using the IKD Zonulin ELISA Kit (Immunodiagnostik AG, Bensheim, Germany). Secretory immunoglobulin A concentrations in stool samples were determined with the Secretory IgA test (ImmuChrom GmbH, Heppenheim, Germany). The minimum sensitivity of the test was $3.1 \mathrm{ng} / \mathrm{ml}$.

The concentrations were measured by means of an immunoenzymatic method (ELISA) with a BioTek PowerWave XS spectrophotometer (USA).

\section{Statistical analysis}

The results are depicted as mean values, standard deviations ( \pm SD). The data were analyzed statistically using the Statistica 13.0 software package (StatSoft, Tulsa, Oklahoma, USA). The normality of the variables was verified with the W Shapiro-Wilk test. The significance of differences between the variables observed before and after the training period in both study groups was assessed by the Wilcoxon matched-pairs test. The significance of differences between the groups was assessed by the nonparametric U Mann-Whitney test, with $p<0.05$ adopted as the threshold for statistical significance.

\section{Results}


There were no significant differences between the two groups for age, body height, body mass, and percentage of body fat. The changes in $\mathrm{VO}_{2 \text { peak }}$ did not differ between the groups during the 4-week study (Table 3).

Table 3

Reference values for selected indicator bacteria and stool $\mathrm{pH}$

\begin{tabular}{|lll|}
\hline Species [Genus] & $\begin{array}{l}\text { Standard } \\
\text { [Log10 CFU/g feces] }\end{array}$ & Method \\
\hline ANAEROBIC & & \\
\hline Bifidobacterium spp. & $\geq 8$ & Real-time PCR \\
\hline Bacteroides spp. & $\geq 9$ & Real-time PCR \\
\hline Faecalibacterium prausnitzii & $\geq 9$ & Real-time PCR \\
\hline Akkermansia muciniphila & $\geq 8$ & Real-time PCR \\
\hline Feces pH & $5.8-6.5$ & \\
\hline
\end{tabular}

Group changes during the 4-week study did not differ significantly for targeted stool bacteria (Table 4).

Table 4

Subject characteristics and pre- and post-study weight, body composition, and VO2peak

\begin{tabular}{|c|c|c|c|c|c|}
\hline & $\begin{array}{l}\text { Pre- } \\
\text { study }\end{array}$ & $\begin{array}{l}\text { Pre-study } \\
E T+S\end{array}$ & $\begin{array}{l}\text { Post- } \\
\text { study }\end{array}$ & $\begin{array}{l}\text { Post-study } \\
\text { ET + S }\end{array}$ & \multirow[t]{3}{*}{$\begin{array}{l}\text { Group difference, change } \\
\text { over } 4 \text { weeks }\end{array}$} \\
\hline & ET & Mean \pm SD & ET & Mean \pm SD & \\
\hline & \multicolumn{2}{|l|}{$\begin{array}{l}\text { Mean } \\
\pm \text { SD }\end{array}$} & \multicolumn{2}{|l|}{$\begin{array}{l}\text { Mean } \\
\pm \text { SD }\end{array}$} & \\
\hline Age (year) & $22 \pm 1$ & $22 \pm 1.5$ & & & \\
\hline Height (cm) & $183 \pm 4$ & $182 \pm 5$ & & & \\
\hline Weight (kg) & $\begin{array}{l}79.0 \pm \\
5.2\end{array}$ & $77.5 \pm 9.9$ & $\begin{array}{l}79.9 \pm \\
5.9\end{array}$ & $78.0 \pm 9.0$ & NS \\
\hline Fat (\%) & $\begin{array}{l}19 \pm \\
5.3\end{array}$ & $21.3 \pm 3.5$ & $\begin{array}{l}18.6 \pm \\
4.7\end{array}$ & $20.3 \pm 3.7$ & NS \\
\hline $\begin{array}{l}\mathrm{VO}_{2} \text { peak } \\
(\mathrm{ml} / \mathrm{kg} / \mathrm{min})\end{array}$ & $\begin{array}{l}51.6 \pm \\
5.5\end{array}$ & $48.2 \pm 8.2$ & $\begin{array}{l}50.8 \pm \\
6.3\end{array}$ & $49.9 \pm 8.8$ & NS \\
\hline
\end{tabular}

NS = non-significant difference

Group changes during the 4-week study did not differ significantly for targeted stool bacteria and stool $\mathrm{pH}$ (Table 5). 
Table 5

Pre- and post-study group comparisons for targeted stool bacteria and stool $\mathrm{pH}$

\begin{tabular}{|c|c|c|c|c|c|}
\hline \multirow[t]{3}{*}{$\begin{array}{l}\text { [Log10 CFU/g } \\
\text { feces] }\end{array}$} & $\begin{array}{l}\text { Pre- } \\
\text { study }\end{array}$ & $\begin{array}{l}\text { Pre-study } \\
\text { ET + S }\end{array}$ & $\begin{array}{l}\text { Post- } \\
\text { study }\end{array}$ & $\begin{array}{l}\text { Post-study } \\
\text { ET + S }\end{array}$ & \multirow[t]{3}{*}{$\begin{array}{l}\text { Group difference, change } \\
\text { over } 4 \text { weeks }\end{array}$} \\
\hline & ET & Mean \pm SD & ET & Mean \pm SD & \\
\hline & $\begin{array}{l}\text { Mean } \\
\pm \text { SD }\end{array}$ & & $\begin{array}{l}\text { Mean } \\
\pm S D\end{array}$ & & \\
\hline $\begin{array}{l}\text { Bifidocacterium } \\
\text { spp. }\end{array}$ & $6 \pm 0.8$ & $6.2 \pm 0.8$ & $\begin{array}{l}6.4 \pm \\
0.9\end{array}$ & $6.2 \pm 0.8$ & NS \\
\hline $\begin{array}{l}\text { Bacteroides } \\
\text { spp. }\end{array}$ & $\begin{array}{l}8.9 \pm \\
0.3\end{array}$ & $8.6 \pm 0.5$ & $9 \pm 0.6$ & $8.7 \pm 0.7$ & NS \\
\hline F. prausnitzii & $\begin{array}{l}8.5 \pm \\
0.3\end{array}$ & $8.5 \pm 0.5$ & $\begin{array}{l}8.5 \pm \\
0.4\end{array}$ & $8.4 \pm 0.7$ & NS \\
\hline A. muciniphila & $3.4 \pm 1$ & $4.1 \pm 2.3$ & $4 \pm 1.9$ & $4.2 \pm 2.2$ & NS \\
\hline Stool pH & $\begin{array}{l}6.1 \pm \\
0.5\end{array}$ & $6.3 \pm 0.3$ & $\begin{array}{l}6.4 \pm \\
0.4\end{array}$ & $6.3 \pm 0.7$ & NS \\
\hline
\end{tabular}

NS = non-significant difference

Group changes during the 4-week study did not differ significantly for stool zonulin, slgA, and hsCRP (Table 6).

Table 6

Pre- and post-study group comparisons for stool zonulin, slgA, and hsCRP

\begin{tabular}{|c|c|c|c|c|c|}
\hline & $\begin{array}{l}\text { Pre- } \\
\text { study }\end{array}$ & $\begin{array}{l}\text { Pre-study } \\
\text { ET + S }\end{array}$ & $\begin{array}{l}\text { Post- } \\
\text { study }\end{array}$ & $\begin{array}{l}\text { Post-study } \\
\text { ET }+S\end{array}$ & \multirow[t]{3}{*}{$\begin{array}{l}\text { Group difference, change ove } \\
4 \text { weeks }\end{array}$} \\
\hline & ET & Mean $\pm S D$ & ET & Mean \pm SD & \\
\hline & $\begin{array}{l}\text { Mean } \pm \\
\text { SD }\end{array}$ & & $\begin{array}{l}\text { Mean } \pm \\
\text { SD }\end{array}$ & & \\
\hline $\begin{array}{l}\text { Zonulin } \\
(\mathrm{ng} / \mathrm{ml})\end{array}$ & $\begin{array}{l}132 \pm \\
119\end{array}$ & $119 \pm 80$ & $\begin{array}{l}289 \pm \\
183\end{array}$ & $228 \pm 179$ & NS \\
\hline $\begin{array}{l}\operatorname{slgA} \\
(\mu \mathrm{g} / \mathrm{ml})\end{array}$ & $\begin{array}{l}1653 \pm \\
1390\end{array}$ & $\begin{array}{l}1385 \pm \\
1408\end{array}$ & $\begin{array}{l}1059 \pm \\
889\end{array}$ & $1784 \pm 1213$ & NS \\
\hline CRP (ng/dl) & $0.7 \pm 1.2$ & $1 \pm 1$ & $\begin{array}{l}1.4 \pm \\
2.5\end{array}$ & $0.4 \pm 0.5$ & NS \\
\hline
\end{tabular}

NS = non-significant difference

Group changes during the 4-week study did not differ significantly for total blood white blood cell (WBC) counts or WBC subsets (Table 7). 
Table 7

Pre- and post-study group comparisons for total white blood cell counts (WBC) and subsets

\begin{tabular}{|c|c|c|c|c|c|}
\hline $\begin{array}{l}\text { Variable, cell count } \\
{\left[10^{9} / \mathrm{L}\right]}\end{array}$ & $\begin{array}{l}\text { Pre- } \\
\text { study } \\
\text { ET }\end{array}$ & $\begin{array}{l}\text { Pre-study } \\
\text { ET +S } \\
\text { Mean } \pm \text { SD }\end{array}$ & $\begin{array}{l}\text { Post- } \\
\text { study } \\
\text { ET }\end{array}$ & $\begin{array}{l}\text { Post-study } \\
\text { ET + S } \\
\text { Mean } \pm \text { SD }\end{array}$ & $\begin{array}{l}\text { Group difference, change } \\
\text { over } 4 \text { weeks }\end{array}$ \\
\hline & $\begin{array}{l}\text { Mean } \\
\pm \text { SD }\end{array}$ & & $\begin{array}{l}\text { Mean } \\
\pm S D\end{array}$ & & \\
\hline $\begin{array}{l}\text { Total white blood } \\
\text { cells (WBC) }\end{array}$ & $6.6 \pm 1$ & $7.9 \pm 3.6$ & $\begin{array}{l}5.8 \pm \\
1.2\end{array}$ & $6.5 \pm 1.5$ & NS \\
\hline Neutrophils & $\begin{array}{l}3.3 \pm \\
0.5\end{array}$ & $4.7 \pm 3.5$ & $\begin{array}{l}2.6 \pm \\
0.9\end{array}$ & $3.2 \pm 1$ & NS \\
\hline Lymphocytes & $\begin{array}{l}2.4 \pm \\
0.8\end{array}$ & $2.1 \pm 0.3$ & $\begin{array}{l}2.3 \pm \\
0.7\end{array}$ & $2.3 \pm 0.4$ & NS \\
\hline Monocytes & $\begin{array}{l}0.5 \pm \\
0.1\end{array}$ & $0.8 \pm 0.2$ & $\begin{array}{l}0.5 \pm \\
0.2\end{array}$ & $0.7 \pm 23.4$ & NS \\
\hline Eosinophils & $\begin{array}{l}0.2 \pm \\
0.1\end{array}$ & $0.2 \pm 0.2$ & $\begin{array}{l}0.2 \pm \\
0.2\end{array}$ & $0.3 \pm 0.4$ & NS \\
\hline Basophils & $\begin{array}{l}0.04 \pm \\
0.1\end{array}$ & $\begin{array}{l}0.03 \pm \\
0.01\end{array}$ & $\begin{array}{l}0.04 \pm \\
0.01\end{array}$ & $0.04 \pm 0.02$ & NS \\
\hline
\end{tabular}

NS = non-significant difference

\section{Discussion}

In this study, participants exercised 60 minutes for three times per week over a 4-week period with or without 30-minute post-exercise dry sauna treatments. Blood and stool samples were collected pre- and post-study. The key finding of the present study is that repeated applications of sauna bathing just after physical training had no effect on targeted gut microbiota, intestinal permeability markers, intestinal barrier function, and inflammation in young adult males.

Microbial diversity can be altered by a variety of environmental factors including diet, altitude, season, temperature, and fitness status (11). And conversely, changes in microbial diversity can influence energy metabolism, behaviour, inflammation, immunity, aging, other physiological processes, and disease states (12).

This study did not include a non-exercise control group and was therefore not designed to investigate exercise training effects on targeted gut microbiota, intestinal permeability, or inflammation. Instead the primary focus was on the influence of post-exercise sauna bathing on gut microbiota during a 4-week exercise training period. The results were not supportive that 30 -minute sauna treatments after 60 -minute exercise bouts altered levels of targeted bacteria from the gut microbiome. 
Animal studies support that remodelling of the gut microbiome is responsive to chronic alterations in both ambient and internal temperature (13);(14), but human data, especially within the context of repeated acute thermal treatments are lacking (10); (15). For example, 24-week-old female mice exposed to $34^{\circ} \mathrm{C}$ for 8 weeks experienced a significant alteration in microbial composition, with increases in several genera including Akkermansia (14). The mechanism by which thermal therapy affects intestinal microbes may in part be related to temperature-related influences on intestinal permeability and related effects on gut-derived metabolites (10). A single layer of epithelial cells connected by tight junctions forms the intestinal barrier that controls transports of metabolites from the lumen to the circulation. With increased body temperature, blood flow to the skin is increased accompanied by vasonconstriction of the GI tract, exerting tensional stress on tight junction and enhancing leakiness of selected metabolites. Intensive and prolonged exercise can also induce intestinal hypoperfusion, dehydration, impaired osmolarity of body fluids and gut motility, and increased permeability of the intestinal barrier (16);(17); (18);(19). Fecal zonulin is a recognized biomarker of intestinal permeability (17). In our study, an increase in zonulin concentration in feces was noted in both groups, but these increases did not differ between groups indicating no added effect of post-exercise sauna bathing. Microbiota imbalances such as low counts for Akkermansia muciniphila and Faecalibacterium prausnitzii have been linked to inflammation (20). The fecal pH level was within the normal range for our subjects, and reflects typical levels of shortchain fatty acid production by gut bacteria (7). Fecal abundance of $A$. muciniphila and F. prausnitzii may increase in response to physical training, but our data did not confirm these findings(21);(22).

Secretory IgA plays an important role in mucosal immunity, can survive in harsh environments such as the $\mathrm{Gl}$, and provides first-line protection against potentially pathogenic microbes (23).Gut slgA imbalances have been lined to various diseases (24). Lifestyle, exercise, stress, and diet can influence slgA levels (25). Study participants had fecal slgA levels within the reference range and changes during the 4-week study did not differ between ET + S and ET groups. Enterococcus spp., Lactobacillus spp. and Bacteroides spp. may have an influence on intestinal inflammation by increasing the expression of tight junction protein and the production and secretion of mucin and antimicrobial peptides (AMPs) that combat pathogenic invasion and stimulate plasmocytes for IgA secretion (26). Our data indicate that 4weeks of exercise training with or without sauna bathing has no influence on slgA secretion by $\mathrm{GI}$ epithelial cells. Additionally, no group differences were observed for measures of inflammation including blood leukocyte subset counts and hsCRP. These data indicate that repeated sessions of post-exercise sauna bathing had no effect on profile of the targeted gut bacteria, immune barrier function or inflammation markers in young males.

\section{Limitation Of The Study}

This study had several limitations. A randomized parallel group design was employed, and subject numbers were low for this type of investigation. However, the selected sample size was big enough to detect changes in the study's primary and secondary outcomes. The exercise training program and sauna treatments included just 12 sessions during a 4-week program, and this may not have been a sufficient physiological stimulus to induce change in the measured outcomes, especially in young adult males. 
Leukocyte subset and hsCRP levels were low pre- and post-study for both groups, indicating that there was little room for exercise training or sauna treatments to exert a measurable effect.

\section{Conclusion}

The combination of 4-weeks exercise training and post-exercise sauna treatments did not have a measurable influence on targeted gut microbiota, intestinal barrier function, and inflammation biomarkers in young males.

This finding does not preclude other benefits linked to exercise training and sauna treatments.

Selected indicators of gut microbiota remained stable during the 4-week exercise training period.

\section{Abbreviations}

AMPs

antimicrobial peptides; VO2peak:peak oxygen uptake, Gl:gastrointestinal; hsCRP:high-sensitivity Creactive protein; NS:non-significant difference; slgA:secretory immunoglobulin A; WBC:total blood white blood cell

\section{Declarations}

\section{Ethical approval}

The study protocol was approved by the Ethics Committee for Human Research at the Poznań University of Medical Sciences (approval no. 173/16 of 4 February 2018) and was performed in accordance with the Declaration of Helsinki. Males provided informed consent.

\section{Consent for publication}

I Joanna Karolkiewicz, on behalf of all co-authors, give my consent for information about myself and coauthors to be published in BMC Sports Science, Medicine and Rehabilitation. I understand that the information will be published without our names attached, but that full anonymity cannot be guaranteed. I understand that the text and any pictures or videos published in the article will be freely available on the internet and may be seen by the general public. The pictures, videos and text may also appear on other websites or in print, may be translated into other languages or used for commercial purposes. I have been offered the opportunity to read the manuscript. Signing this consent form does not remove my rights to privacy.

\section{Availability of data and materials}

The datasets generated during and/or analysed during the current study are available from the corresponding author on reasonable request. 


\section{Competing interests}

The authors declare that they have no competing interests.

\section{Funding}

The study was sponsored partly by a grant No PB.501-1/2018 obtained from the State University of Applied Sciences in Nowy Sącz and partly by a grant MNiSW - Development of young researchers obtained from the Poznan University of Physical Education.

\section{Authors' contributions}

J.K. substantial contributions to conception and design, analysis and interpretation of data, was a major contributor in writing the manuscript and final approval of the version to be published; D.C. N. revising article critically for important intellectual content; T.C. conducted training and sauna procedures, collected blood and faeces samples, acquisition; J. S. acquisition of data, prepared tables; M.G. carried out faeces analyses, reviewed the manuscript, D.S. carried out performance tests; Z.S. was a major contributor in writing the manuscript and final approval of the version to be published.

\section{Acknowledgments}

We would like to thank the volunteers for their participation in the research project and for their time. We also thank dr. Michał Starczewski from the Department of Physiology, Institute of Sport - National Research Institute, Warsaw, Poland for his excellent technical assistance.

\section{References}

1. Crowther F, Sealey R, Crowe M, Edwards A, Halson S. Team sport athletes' perceptions and use of recovery strategies: A mixed-methods survey study. BMC Res Notes. 2017;10(1):1-10.

2. Hussain J, Cohen M. Clinical Effects of Regular Dry Sauna Bathing: A Systematic Review. Evidencebased Complement Altern Med. 2018;2018.

3. Laukkanen JA, Laukkanen T, Kunutsor SK. Cardiovascular and Other Health Benefits of Sauna Bathing: A Review of the Evidence. Mayo Clin Proc [Internet]. 2018;93(8):1111-21. Available from: https://doi.org/10.1016/j.mayocp.2018.04.008

4. Novak D, Tudor PB, Matkovic BR. Adding Sauna Bathing After Endurance Training: a Practical Insight From the Word'S Top Junior Tennis Player. Acta Kinesiol. 2018;12(1):50-54.

5. Scoon GSM, Hopkins WG, Mayhew S, Cotter JD. Effect of post-exercise sauna bathing on the endurance performance of competitive male runners. J Sci Med Sport. 2007;10(4):259-62.

6. Gerdes V, Gueimonde M, Pajunen L, Nieuwdorp M, Laitinen K. How strong is the evidence that gut microbiota composition can be influenced by lifestyle interventions in a cardio-protective way? Atherosclerosis [Internet]. 2020;311(June):124-42. Available from:

https://doi.org/10.1016/j.atherosclerosis.2020.08.028 
7. Hughes RL. A Review of the Role of the Gut Microbiome in Personalized Sports Nutrition. Front Nutr. 2020;6(January).

8. Mohr AE, Jäger R, Carpenter KC, Kerksick CM, Purpura M, Townsend JR, et al. the Gut Athelte. Journal of the International Society of Sports Nutrition; 2020. 1-33 p.

9. Costa RJS, Gaskell SK, McCubbin AJ, Snipe RMJ. Exertional-heat stress-associated gastrointestinal perturbations during Olympic sports: Management strategies for athletes preparing and competing in the 2020 Tokyo Olympic Games. Temperature [Internet]. 2020;7(1):58-88. Available from: https://doi.org/10.1080/23328940.2019.1597676

10. Hylander BL, Repasky EA. Temperature as a modulator of the gut microbiome: what are the implications and opportunities for thermal medicine? Int J Hyperth [Internet]. 2019;36(sup1):83-9. Available from: https://doi.org/10.1080/02656736.2019.1647356

11. Karl PJ, Hatch AM, Arcidiacono SM, Pearce SC, Pantoja-Feliciano IG, Doherty LA, et al. Effects of psychological, environmental and physical stressors on the gut microbiota. Front Microbiol. 2018;9(SEP):1-32.

12. Lobionda S, Sittipo P, Kwon HY, Lee YK. The role of gut microbiota in intestinal inflammation with respect to diet and extrinsic stressors. Microorganisms. 2019;7(8).

13. Chevalier C, Stojanović O, Colin DJ, Suarez-Zamorano N, Tarallo V, Veyrat-Durebex C, et al. Gut Microbiota Orchestrates Energy Homeostasis during Cold. Cell. 2015;163(6):1360-74.

14. Chevalier C, Kieser S, Çolakoğlu M, Hadadi N, Brun J, Rigo D, et al. Warmth Prevents Bone Loss Through the Gut Microbiota. Cell Metab. 2020;32(4):575-590.e7.

15. Zhang XY, Sukhchuluun G, Bo TB, Chi QS, Yang JJ, Chen B, et al. Correction: Huddling remodels gut microbiota to reduce energy requirements in a small mammal species during cold exposure [Microbiome., 6, (2018) (103)] DOI: 10.1186/s40168-018-0473-9. Microbiome. 2018;6(1):1-14.

16. Fasano A. Physiological, pathological, and therapeutic implications of zonulin-mediated intestinal barrier modulation: Living life on the edge of the wall. Am J Pathol. 2008;173(5):1243-52.

17. Takiishi T, Fenero CIM, Câmara NOS. Intestinal barrier and gut microbiota: Shaping our immune responses throughout life. Tissue Barriers. 2017;5(4).

18. Ulluwishewa D, Anderson RC, McNabb WC, Moughan PJ, Wells JM, Roy NC. Regulation of tight junction permeability by intestinal bacteria and dietary components. J Nutr. 2011;141(5):769-76.

19. Biedunkiewicz A. Moulds isolated from the upper sections of the respiratory and alimentary tracts of healthy veterinary medicine students. Med Pr. 2011;62(3):259-25967.

20. Macfarlane GT, Steed H, Macfarlane S. Bacterial metabolism and health-related effects of galactooligosaccharides and other prebiotics. J Appl Microbiol. 2008;104(2):305-44.

21. Keohane DM, Woods T, O'Connor P, Underwood S, Cronin O, Whiston R, et al. Four men in a boat: Ultra-endurance exercise alters the gut microbiome. J Sci Med Sport [Internet]. 2019;22(9):1059-64. Available from: https://doi.org/10.1016/j.jsams.2019.04.004 
22. Rengarajan S, Knoop KA, Rengarajan A, Chai JN, Grajales-Reyes JG, Samineni VK, et al. A Potential Role for Stress-Induced Microbial Alterations in IgA-Associated Irritable Bowel Syndrome with Diarrhea. Cell Reports Med [Internet]. 2020;1(7):100124. Available from: https://doi.org/10.1016/j.xcrm.2020.100124

23. Levy M, Kolodziejczyk AA, Thaiss CA, Elinav E. Dysbiosis and the immune system. Nat Rev Immunol [Internet]. 2017;17(4):219-32. Available from: http://dx.doi.org/10.1038/nri.2017.7

24. Davison G, Kehaya C, Wyn Jones A. Nutritional and Physical Activity Interventions to Improve Immunity. Am J Lifestyle Med. 2016;10(3):152-69.

25. Caballero-Franco C, Keller K, De Simone C, Chadee K. The VSL\#3 probiotic formula induces mucin gene expression and secretion in colonic epithelial cells. Am J Physiol - Gastrointest Liver Physiol. 2007;292(1):315-22.

26. Macpherson AJ, Yilmaz B, Limenitakis JP, Ganal-Vonarburg SC. IgA Function in Relation to the Intestinal Microbiota. Annu Rev Immunol. 2018;36:359-81. 